\title{
MOLECULAR EVOLUTION OF GPCRS Melanocortin/melanocortin receptors
}

\author{
Robert M Dores, Richard L Londraville', Jeremy Prokop ${ }^{1}$, Perry Davis, \\ Nathan Dewey and Natalie Lesinski
}

Department of Biological Sciences, University of Denver, Denver, Colorado 80210, USA

${ }^{1}$ Department of Biology, University of Akron, Akron, Ohio 44325, USA
Correspondence should be addressed to R M Dores

Email

rdores@du.edu

\begin{abstract}
The melanocortin receptors (MCRs) are a family of G protein-coupled receptors that are activated by melanocortin ligands derived from the proprotein, proopiomelanocortin (POMC). During the radiation of the gnathostomes, the five receptors have become functionally segregated (i.e. melanocortin 1 receptor (MC1R), pigmentation regulation; MC2R, glucocorticoid synthesis; MC3R and MC4R, energy homeostasis; and MC5R, exocrine gland physiology). A focus of this review is the role that ligand selectivity plays in the hypothalamus/pituitary/adrenal-interrenal (HPA-I) axis of teleosts and tetrapods as a result of the exclusive ligand selectivity of MC2R for the ligand ACTH. A second focal point of this review is the roles that the accessory proteins melanocortin 2 receptor accessory protein 1 (MRAP1) and MRAP2 are playing in, respectively, the HPA-I axis (MC2R) and the regulation of energy homeostasis by neurons in the hypothalamus (MC4R) of teleosts and tetrapods. In addition, observations are presented on trends in the ligand selectivity parameters of cartilaginous fish, teleost, and tetrapod MC1R, MC3R, MC4R, and MC5R paralogs, and the modeling of the HFRW motif of ACTH(1-24) when compared with $\alpha-\mathrm{MSH}$. The radiation of the MCRs during the evolution of the gnathostomes provides examples of how the physiology of endocrine and neuronal circuits can be shaped by ligand selectivity, the intersession of reverse agonists (agouti-related peptides (AGRPs)), and interactions with accessory proteins (MRAPs).
\end{abstract}

$\begin{aligned} & \text { Key Words } \\ & \text { - melanocortin receptors } \\ & \text { - } \mathrm{MC2R} \\ & \text { - MC4R } \\ & \text { - melanocortin peptides } \\ & \text { - } \mathrm{ACTH} \\ & \text { - } \alpha-\mathrm{MSH} \\ & \text { - MRAP1 } \\ & \text { - MRAP2 }\end{aligned}$

Journal of Molecular Endocrinology (2014) 52, T29-T42

\section{Introduction}

The evolution of endocrine and neuronal melanocortin receptor (MCR)-mediated circuits has been shaped by the co-evolution of the MCR gene family, the proopiomelanocortin (pomc) gene, and the genes that code for polypeptides that either interact with the receptors as reverse agonists (i.e. agouti and agouti-related peptide (AGRP); Cone 2006) or serve as accessory proteins for the
MCRs (i.e. melanocortin 2 receptor accessory protein 1 (MRAP1) and MRAP2; Hinkle \& Sebag 2009, Webb \& Clark 2010). A number of studies have determined the pharmacological features of ligand selectivity for MCRs expressed in heterologous mammalian cell lines. How well do these pharmacological properties reflect the physiological roles of the MCRs? To this end, this review will summarize the 
results of ligand selectivity studies done on MCRs expressed in heterologous cells lines, and then consider the role that ligand selectivity plays in the physiology of two MCR-mediated circuits: hypothalamus/pituitary/ adrenal-interrenal (HPA-I) axis (melanocortin 2 receptor (MC2R)), and the regulation of energy homeostasis by neurons in the hypothalamus (MC4R). For both physiological circuits, the role of MRAPs will be discussed.

\section{Overview of MCRs and ligands}

Five MCRs have been detected in the genomes of gnathostomes (i.e. cartilaginous fishes, bony fishes, and tetrapods). As reviewed by Cone (2006), the receptor gene family was first characterized for mammals, and the receptor genes were named based on their order of discovery, and in some cases, the physiological processes commonly associated with each receptor (Gantz \& Fong 2003, Cone 2006), as summarized in Fig. 1. For example, $\mathrm{MC1R}$, also referred to as the 'MSH' receptor is expressed on melanocytes and melanophores. This receptor is involved in pigmentation and physiological color change. MC2R, the 'adrenocorticotropic hormone' (ACTH) receptor, is expressed on the adrenal cortex cells of reptiles, birds, and mammals and the interrenal cells of amphibians and bony fishes, and is involved in glucocorticoid synthesis via the HPA-I axis. MC3R and MC4R are expressed on neurons in the hypothalamus and play a role in the regulation of energy homeostasis (Cone 2006). Finally, MC5R is expressed by some exocrine gland cells and plays a role in the physiology of those glands (Cone 2006). As shown in Fig. 1, the MCRs have seven membrane-spanning domains and are members of the

\begin{tabular}{|c|c|c|}
\hline & Human melanocortin receptors & Primary functions \\
\hline MC1R & \begin{tabular}{|l|l||l|l}
4 & 5 & 6 & 7 \\
\end{tabular} & Pigmentation \\
\hline MC2R & \begin{tabular}{|l|l||l|l|}
4 & 5 & 6 & 7 \\
\end{tabular} & Glucocorticoid biosynthesis \\
\hline MC3R & \begin{tabular}{|l|l|l|l|l|}
4 & 5 & 6 & 7 \\
\end{tabular} & Energy homeostasis \\
\hline IC4R & \begin{tabular}{|l|l|l|l|l|l|l|}
1 & 2 & 3 & 4 & 5 & 6 & 7 \\
\end{tabular} & Energy homeostasis \\
\hline IC5R & \begin{tabular}{l|l|l|l|l|l|l|l}
1 & 2 & 3 & 4 & 5 & 6 & 7
\end{tabular} & Exocrine gland regulation \\
\hline
\end{tabular}

Figure 1

Schematic of human melanocortin receptors (MCRs). These cartoons of human MCRs are roughly drawn to scale to show the positioning of the seven transmembrane-spanning domains (red numbered boxes), and the relative size of the $\mathrm{N}$-terminal domains (blue boxes), and the $\mathrm{C}$-terminal domains (green boxes) for each receptor. The functions ascribed for each receptor are adapted from Gantz \& Fong (2003).
A-13 family within the rhodopsin class of $G$ proteincoupled receptors (GPCRs; Horn et al. 2003, Vassilatis et al. 2003). When compared with other GPCRs, the MCRs are the smallest in terms of primary sequence, with relatively short $\mathrm{N}$ - and C-terminal domains (Horn et al. 2003). The reduction in the size of the N-terminal domain is most pronounced for teleost and tetrapod MC2R orthologs (Mountjoy et al. 1992, Schiöth et al. 2005).

To date, MCR genes have only been detected in the genomes of chordates (Vastermark \& Schiöth 2011) and the presence of five paralogous $\mathrm{mcr}$ genes in the genomes of jawed vertebrates (gnathostomes) appears to be the result of the two genome duplication events that have shaped the radiation of the chordates (Ohno et al. 1968, Holland et al. 1994) and at least one local gene duplication event. MC5R is believed to be the result of the local gene duplication event; however, the mor gene that was duplicated to give rise to MC5R has been a debated topic in the literature. For alternative views on this subject, please see Klovins et al. $(2004 a, b)$, Vastermark \& Schiöth (2011), and Dores (2013).

The melanocortin peptides that activate MCRs are derived from the precursor protein POMC (Nakanishi et al. 1979). This precursor encodes multiple ligands with the melanocortin core sequence (HFRW), such as ACTH, $\alpha$-MSH, $\beta$-MSH, $\gamma$-MSH, and $\delta$-MSH (Takahashi et al. 2004, Dores \& Lecaude 2005). POMC is a member of the opioid/orphanin gene family, and the evolution and phylogeny of this gene family in chordates have been extensively reviewed over the past 10 years (Dores et al. 2002, Sundstrom et al. 2010, Dores \& Baron 2011). Among the gnathostomes, the organization of this precursor and the sequences of the melanocortin peptides have been conserved as shown in Fig. 2. In addition, the expression of the pomc gene in the anterior and intermediate pituitary as well as the hypothalamus of gnathostomes, and the post-translational processing of this precursor in these regions of the pituitary and brain have also been remarkably conserved (Vallarino et al. 2012). In brief, the organization of chemical signals in POMC minimally includes an $\mathrm{ACTH} / \alpha$-MSH sequence $(\alpha-\mathrm{MSH}$ comprises the first 13 amino acids in the ACTH sequence), a $\beta$-MSH sequence, and a $\beta$-endorphin sequence (endogenous opioid peptide; Dores \& Lecaude 2005, Fig. 2). In tetrapods and the cartilaginous fishes, the N-terminal region of the precursor has a $\gamma$-MSH sequence (Fig. 2), and in cartilaginous fishes there is an additional $\delta$-MSH sequence in the C-terminal region of the precursor (Takahashi \& Kawauchi 2006, Fig. 2). For teleosts, the $\gamma$-MSH sequence has been deleted, but $\mathrm{ACTH} / \alpha-\mathrm{MSH}$ and $\beta$-MSH sequences have

Published by Bioscientifica Ltd 
Examples of the organizational plan for POMC

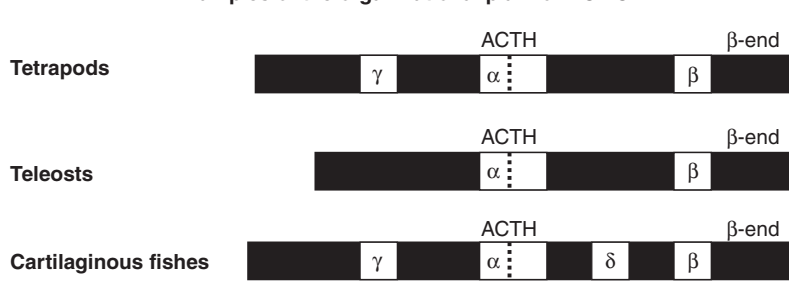

Cartilaginous fish (dogfish) melanocortins

ACTH SYSMEHFRWGKPMGRKRRPIKVYPNSFEDESVENMGPEL

$\alpha$-MSH SYSMEHFRWGKPM

$\beta$-MSH DGDDYKFGHFRWSVPKD

$\gamma$-MSH SYVMGHFRWNKF

$\delta$-MSH DGKIYKMTHFRW

\section{Figure 2}

Schematic of the organization of gnathostome POMC. These cartoons (not drawn to scale) show the POMC organizational plan for tetrapods, teleosts, and cartilaginous fishes. All POMC sequences have a single copy of the $\beta$-endorphin sequence located at the $\mathrm{C}$-terminal of the precursor. Tetrapod POMCs have a $\gamma$-MSH $(\gamma)$ sequence in the $\mathrm{N}$-terminal of the precursor, an $\mathrm{ACTH} / \alpha$-MSH $(\alpha)$ sequence in the middle of the precursor, and a $\beta$-MSH ( $\beta$ ) sequence near the C-terminal of the precursor. Teleost POMCs lack a $\gamma-\mathrm{MSH}$, but have retained the $\mathrm{ACTH} / \alpha-\mathrm{MSH}$ and the $\beta-\mathrm{MSH}$ sequences. Cartilaginous fish POMCs have retained the $\gamma-\mathrm{MSH}, \mathrm{ACTH} /$ $\alpha-\mathrm{MSH}$, and the $\beta$-MSH sequences and have an additional $\delta$-MSH $(\delta)$ sequence $\mathrm{N}$-terminal to the $\beta$-MSH sequence. The sequences of dogfish (Amemiya et al. 1999) melanocortins are shown. The HFRW motif is highlighted in red and the RKRRP motif in green.

been retained (Fig. 2). With respect to the post-translational processing of $\mathrm{POMC}$, in the anterior pituitary, the melanocortin end product is ACTH, whereas in the intermediate pituitary and the hypothalamus, the melanocortin end products are the smaller melanocortin peptides (i.e. $\alpha$-MSH, $\beta$-MSH, $\gamma$-MSH, and $\delta$-MSH; Eipper \& Mains 1980, Arends et al. 1998, Takahashi et al. 2001).

Using cartilaginous fish melanocortin peptides as a model, there are two critical primary sequence motifs in these ligands (Fig. 2). All melanocortin peptides have the HFRW motif. This motif is required for activation of all the MCRs (Schwyzer 1977, Cone 2006). As a result, all MCRs must have an HFRW-binding site. Using a modeling analysis approach and a site-directed mutagenesis paradigm, Pogozheva et al. (2005) identified specific residues in the TM2, TM3, TM6, and TM7 domains of human MC4R that constitute the HFRW-binding site for this receptor. Approximately $80 \%$ of these residues are conserved in the MC1R, MC3R, MC4R, and MC5R paralogs of the teleost and tetrapod MCRs that have been characterized, and several of these residues have been conserved in the MC2R orthologs of teleosts and tetrapods (Baron et al. 2009, Dores 2009). The second critical amino acid motif, the
K/RKRRP motif, is only found in the sequence of ACTH (Fig. 2; Schwyzer 1977, Costa et al. 2004). Schwyzer (1977) referred to these residues as the 'address' sequence; a motif that selectively binds to the 'ACTH' receptor (i.e. MC2R) to initiate the activation process. Hence, it is postulated that there is a unique K/RKRRP-binding site on teleost and tetrapod MC2R orthologs (Schwyzer 1977, Liang et al. 2013a).

\section{Studies on the structure of $\alpha-\mathrm{MSH}$ and ACTH(1-24)}

Of the four MSH-sized ligands that have been identified in gnathostomes (Fig. 2), $\alpha$-MSH is the most conserved ligand in terms of primary sequence. In addition, the primary sequence of the first 24 amino acids of ACTH has also been highly conserved in gnathostomes ranging from the cartilaginous fishes to humans (Dores \& Baron 2011). Furthermore, mammalian ACTH(1-24) has been found to be equivalent in potency to mammalian ACTH(1-39) (Schwyzer 1977). Hence, for pharmacological studies on ligand selectivity, MCR cDNAs have been functionally expressed in a number of mammalian cell lines (e.g. HEK293, Chinese hamster ovary (CHO), and Hela; see section 'Pharmacological studies of MCRs'), and stimulated with either mammalian ACTH(1-24), $\alpha-\mathrm{MSH}$, or the analog of mammalian $\alpha-\mathrm{MSH}$, NDP-MSH (Sawyer et al. 1980). Several of these ligand selectivity studies have also used species-specific $\beta$-MSH, $\gamma$-MSH, and $\delta$-MSH ligands (see section 'Pharmacological studies of MCRs').

With regard to the way that melanocortin peptides interact with the MCRs, the structure of the HFRW motif has been of particular interest. Modeling studies to predict the structure of the HFRW motif within $\alpha$-MSH have concluded that this motif forms a reverse $\beta$-turn (see review by Haslach et al. (2009)). While it is assumed that the HFRW motif in ACTH(1-24) would also form a reverse $\beta$-turn, the analysis has apparently not been done. As a result, modeling of the secondary structure for the $\mathrm{R} / \mathrm{KKRRP}$ motif in ACTH(1-24) has also not been determined.

To address these issues, the amino acid sequences for ACTH(1-24) from the rainbow trout (Oncorhynchus mykiss), the dogfish (Squalus acanthias), the African clawed frog (Xenopus laevis), and human were submitted to $a b$ initio modeling of tertiary structure using the QUARK algorithm (Fig. 3). Quark models the tertiary structure of small peptides using a database of all possible phi/psi peptide-bond angles that exist in empirically derived structures; it is one of the best performing algorithms to

Published by Bioscientifica Ltd 


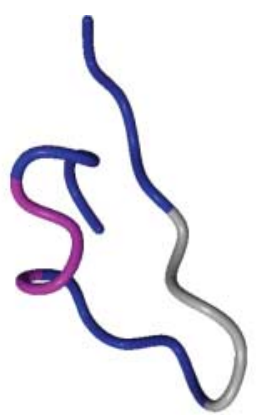

Trout 1

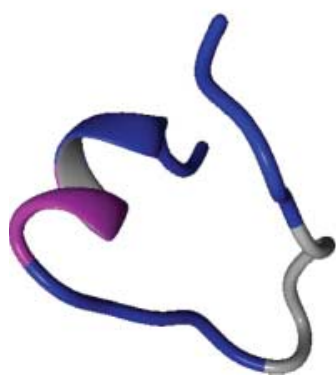

Human 1

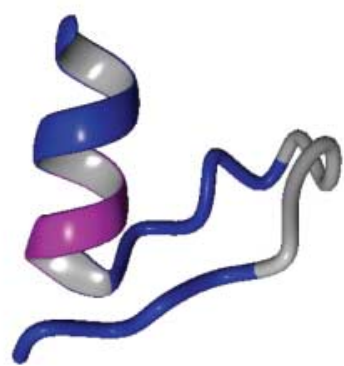

Trout 2

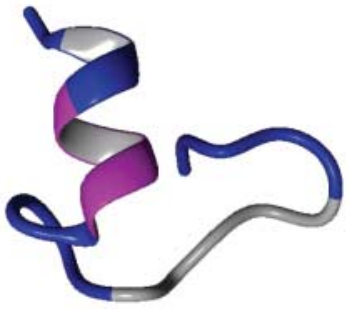

Human 2

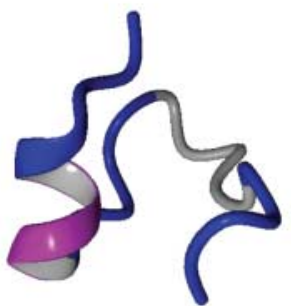

Dogfish 1

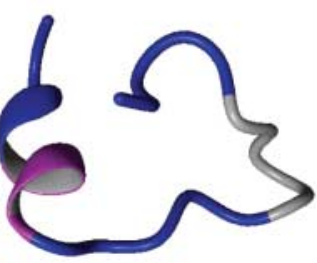

Xenopus 1

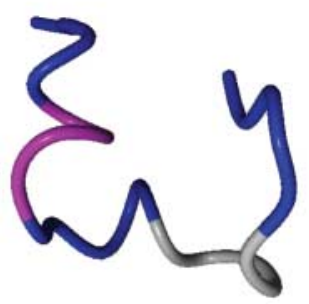

Dogfish 2

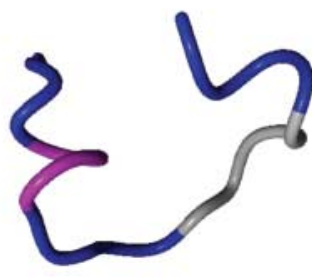

Xenopus 2
Figure 3

In-silico simulations of ACTH(1-24) tertiary structure from rainbow trout (Oncorhynchus mykiss, ACC \#Q04617), dogfish (Squalus acanthias, ACC \#P01197), African clawed frog (Xenopus laevis ACC \#NP_001080838), and human (ACC \#NP_001030333). Sequences were submitted to ab initio modeling via the Quark algorithm (Xu \& Zhang 2012), which returned many similar structures per species. Models 1 and 2 represent two possible structures generated from $a b$ initio modeling, followed by extensive

date (i.e. it can reproduce empirically derived structures from primary sequence alone; Xu \& Zhang 2012).

Several models were returned for each sequence (Fig. 3); all were very similar in structure, and therefore only the first two models per species were analyzed further. Each model was then imported into the YASARA Software (v. 12.7.16; Vienna, Austria) for energy minimization simulation (de Groot et al. 1997). Simulations were run using the AMBER03 force field in an aqueous environment for $>100000$ NS of simulation time.

Over this simulation time, the plateau of the average root-mean-square deviation (RMSD) of all $\alpha$-carbon bonds ranged from 3 to $6 \AA$, indicating significant flexibility of the structure (also seen in the variety of structures in Fig. 3). However, the HFRW motif was considerably more stable than the entire 1-24 sequence, with an RMSD of its $\alpha$-carbon bonds $<2 \AA$. This stability of the HFRW motif (shown in magenta in Fig. 3) is not the result of a uniform secondary structure (either it is a reverse turn or helix), but energy minimization simulation. From this population of models, we can draw inference about general ACTH(1-24) structure among vertebrates. The first two structures per species were energy minimized using the YASARA Software (de Groot et al. 1997) over 100000 NS. The HFRW motif is shown in magenta and the R/KKRRP motif in gray. HFRW is more constrained than the rest of the structures and maintains a uniform distance from R/KKRRP in all but one structure (rainbow trout model 1).

it is indicative that the HFRW motif is constrained, that is, the HFRW motif is not in an open conformation, similar to amino acid positions 1-5 (Fig. 3).

The R/KKRRP motif (shown in gray in Fig. 3) has a generally open structure. In addition, HFRW and KKRRP are separated by GKPVG, at a uniform distance. In all cases but one, the $\alpha$-carbon of $\mathrm{H}^{6}$ is separated from the $\alpha$-carbon of $\mathrm{P}^{12}$ by $80 \AA$ (the one exception is $86 \AA$ ). These simulation experiments support a hypothesis that proposes that the structure of ACTH(1-24) is probably flexible enough to be influenced by binding to the MC2R. However, the motifs in ACTH(1-24) known to be functionally important (HFRW, KKRRP, and GKPVG) are constrained in structure and in relative position to each other. As a result, this model predicts that ACTH(1-24), but not $\alpha-\mathrm{MSH}$, can be accommodated in this binding site. Independent amino acid-substitution experiments in each of the motifs are consistent with this model (see review by Liang et al. (2013a)).

Published by Bioscientifica Ltd 


\section{Pharmacological studies of MCRs}

Pharmacological studies have now been carried out on MCRs from tetrapods, teleosts, cartilaginous fishes, and a jawless fish (lamprey; Haitina et al. 2007). This section will first consider ligand selectivity studies for MC1R, MC3R, MC4R, and MC5R from tetrapods, teleosts, and cartilaginous fishes. The focus will then shift to ligand selectivity studies of MC2R orthologs from tetrapods, teleosts, and a cartilaginous fish.

Ligand selectivity studies on mammalian MCRs before 2005 have been reviewed by Gantz \& Fong (2003), and the potencies of ACTH, $\alpha$-MSH, $\beta-\mathrm{MSH}$, and $\gamma$-MSH are presented in Table 1 , which may initially appear counterintuitive. For example, the 'MSH' receptor (MC1R) can be stimulated by either $\alpha$-MSH or ACTH with an equal potency. However, this pharmacological observation is not that surprising to give the identical primary sequences for the first 13 amino acids of both ligands and predictions of a similar secondary structure for the HFRW motif in each ligand (Fig. 3). The lower potencies of $\beta$-MSH and $\gamma$-MSH would appear to be the result of primary sequence differences around the HFRW motif, when compared with $\alpha$-MSH and ACTH, and the presumed secondary binding sites that flank the HFRW-binding site on MC1R. An identical hierarchy of potency was observed for mammalian MC4R. As shown in Table 1, only mammalian MC5R has a clear preference for $\alpha$-MSH when compared with $\mathrm{ACTH}$, and mammalian MC3R has no preference for the four mammalian melanocortin ligands (i.e. all ligands are equipotent). Are these potency relationships true for all non-mammalian tetrapods (i.e. birds, reptiles, and amphibians)?

Ling et al. (2004) conducted a pharmacological study on the MCRs of a bird (Gallus gallus; chicken) and observed that when binding affinity was used as the criterion, avian MC1R, MC3R, MC4R, and MC5R had a higher affinity for
ACTH(1-24) than $\alpha$-MSH. However, in activation assays (production of cAMP in MCR-transfected cells), it appears that $\mathrm{ACTH}(1-24)$ and $\alpha$-MSH were statistically equipotent. In this study, the potencies of $\beta$-MSH and $\gamma$-MSH were not tested.

Might ACTH be the preferred ligand for activation of non-amniote tetrapod MCRs? To test this possibility, ligand selectivity studies were carried out on MC1R, MC3R, MC4R, and MC5R present in the genome of the amphibian, Xenopus tropicalis (http://genome.jgi-psf.org/ Xentr4/Xentr4.home.html). The X. tropicalis MCR cDNAs were functionally expressed separately in CHO cells (Figs 4 and 5) and stimulated with $X$. tropicalis melanocortin peptides as described in the legend to Fig. 4. The results are summarized in Table 1 and Fig. 5. For frog MC1R, ACTH, $\alpha-\mathrm{MSH}$, and $\beta$-MSH are equipotent and statistically better ligands than $\gamma$-MSH. For frog MC3R, ACTH and $\beta$-MSH are equipotent, and both peptides are statistically better ligands than $\alpha$-MSH and $\gamma$-MSH. Frog MC4R cannot distinguish between ACTH, $\alpha$-MSH, and $\beta$-MSH; however, all three peptides are statistically more potent than $\gamma$-MSH. For frog MC5R, ACTH(1-24) was clearly a more potent ligand than any of the MSH-sized ligands.

While it would appear that tetrapod MC1R, MC3R, MC4R, and MC5R in general respond to ACTH(1-24) and $\alpha$-MSH in an equipotent manner when expressed in heterologous mammalian cell lines, a study on the MCRs of the teleost Takifugu rubripes (Fugu) convincingly showed that ACTH, rather than $\alpha-\mathrm{MSH}$, is a more potent ligand for the MC1R, MC4R, and MC5R paralogs of that species (Klovins et al. 2004a, n.b. the Fugu genome lacks a $m c 3 r$ gene). Similar results were observed for the MC4R and MC5R paralogs of rainbow trout (Haitina et al. 2004) and of the zebrafish (Ringholm et al. 2002). These observations prompted the prediction that ACTH may have been the ancestral ligand for the gnathostome MCRs (Schiöth et al. 2005).

Table 1 Comparison of ligand selectivity for mammalian and Xenopus tropicalis melanocortin receptors

\begin{tabular}{|c|c|c|}
\hline & \multicolumn{2}{|c|}{ Ligand potency } \\
\hline & Mammals $^{a}$ & Frog $^{b}$ \\
\hline MC1R & $\alpha-\mathrm{MSH}=\mathrm{ACTH}>\beta-\mathrm{MSH}>\gamma-\mathrm{MSH}$ & $\mathrm{ACTH}=\alpha-\mathrm{MSH}=\beta-\mathrm{MSH}>\gamma-\mathrm{MSH}$ \\
\hline $\mathrm{MC} 2 \mathrm{R}$ & ACTH only & ACTH only \\
\hline MC3R & $\alpha-\mathrm{MSH}=\beta-\mathrm{MSH}=\gamma-\mathrm{MSH}=\mathrm{ACTH}$ & $\mathrm{ACTH}=\beta-\mathrm{MSH}>\alpha-\mathrm{MSH}=\gamma-\mathrm{MSH}$ \\
\hline MC4R & $\alpha-\mathrm{MSH}=\mathrm{ACTH}>\beta-\mathrm{MSH}>\gamma-\mathrm{MSH}$ & $\mathrm{ACTH}=\alpha-\mathrm{MSH}=\beta-\mathrm{MSH}>\gamma-\mathrm{MSH}$ \\
\hline MC5R & $\alpha-\mathrm{MSH}>\mathrm{ACTH}>\beta-\mathrm{MSH}>\delta-\mathrm{MSH}$ & $\mathrm{ACTH}>\alpha-\mathrm{MSH}=\beta-\mathrm{MSH}=\gamma-\mathrm{MSH}$ \\
\hline
\end{tabular}

a Modified from Gantz \& Fong (2003).

${ }^{\mathrm{b}} \mathrm{X}$. tropicalis (summarized from Fig. 5).

http://jme.endocrinology-journals.org DOI: 10.1530/JME-14-0050 (c) 2014 Society for Endocrinology Printed in Great Britain
Published by Bioscientifica Ltd 

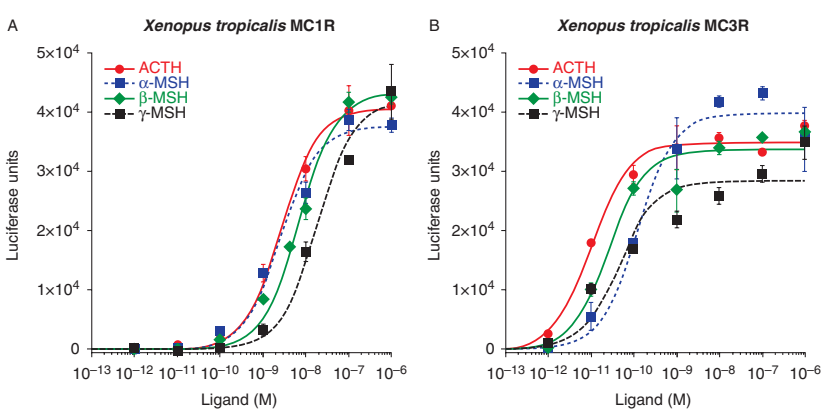

Ligand (M)
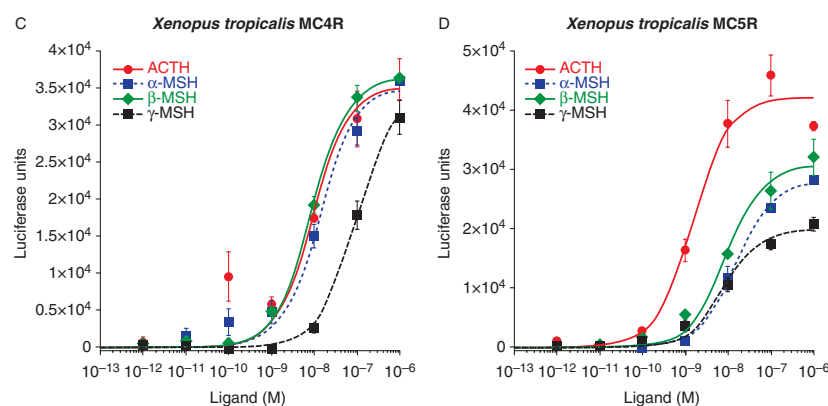

Figure 4

Ligand selectivity of Xenopus tropicalis melanocortin receptors (MCRs): MC1R, MC3R, MC4R, and MC5R. The dose-response curves for $X$. tropicalis MCRs stimulated with either $X$. tropicalis ACTH(1-24), $\alpha-\mathrm{MSH}, \beta-\mathrm{MSH}$, or $\gamma$-MSH are presented for (A) MC1R; (B) MC3R; (C) MC4R; and (D) MC5R). The $X$. tropicalis MCR plasmids were separately transiently transfected into $\mathrm{CHO}$ cells with the CAMP reporter plasmid CRE-luciferase (Chepurny \& Holz 2007) using a Cell Line Nucleofector Solution T Kit (Amaxa, Inc., www. lonza.com) as described by Liang et al. (2011). The cells were plated on a 96-well plate at a density of $1 \times 10^{5}$ cells/well and stimulated $48 \mathrm{~h}$ after transfection with the ligands listed above (New England Peptide, Boston, MA, USA) in serum-free $\mathrm{CHO}$ media for $4 \mathrm{~h}$ at $37^{\circ} \mathrm{C}$ at concentrations

Subsequent studies on MCRs cloned from the genomes of cartilaginous fishes provide support for this prediction. Studies on MC3R from the dogfish, S. acanthias (Klovins et al. 2004b), MC4R from the dogfish (Ringholm et al. 2003), MC5R from the dogfish (Reinick et al. 2012a), and MC3R from the elephant shark, Callorhinchus milii (Liang et al. 2013b) all found that ACTH was a much more potent ligand than any of the cartilaginous MSH-sized peptides. It would appear that the trend in gnathostome evolution has been to move from MC1R, MC3R, MC4R, and MC5R paralogs that have a higher affinity for ACTH relative to the MSH-sized ligands, as observed in the extant cartilaginous fish and teleost MCRs, to MCRs with an equal or greater affinity for $\alpha$-MSH and ACTH as observed for mammalian and avian MC1R, MC3R, MC4R, and MC5R.

While it has been very straightforward to functionally express gnathostome MC1R, MC3R, MC4R, and MC5R in heterologous mammalian cell lines, the initial functional expression of human MC2R could only be achieved when the receptor cDNA construct was expressed in Cloudman 9 S91 melanoma cells, a cell line that also expressed MC1R (Mountjoy et al. 1992). In this regard, a series of studies verified that mammalian MC2R orthologs could not be functionally expressed in non-adrenal-derived cell lines or cells that did not express a MCR (Rached et al. 2005, Forti et al. 2006, Kilianova et al. 2006, Roy et al. 2007). In these studies, the MC2R ortholog never appeared to leave the ranging from $10^{-6}$ to $10^{-12} \mathrm{M}$. After a $4 \mathrm{~h}$ incubation period, $100 \mu \mathrm{l}$ of Bright-Glo luciferase assay reagent (Promega, Inc.) were applied to each well and incubated at room temperature for $5 \mathrm{~min}$. Luminescence was then measured using a Bio-Tek Synergy HT plate reader (Winooski, VT, USA). Previous studies have provided evidence that the $\mathrm{CHO}$ cells used in this study do not endogenously express mrap genes (Reinick et al. 2012b). All dose-response curves were done in triplicate. Average values and S.E.M. were graphed using the KaleidaGraph Software (www.synergy.com), and the $\mathrm{EC}_{50}$ value for each ligand was determined. The curves were not constrained through the $0 / 0$ origin. The $\mathrm{EC}_{50}$ values were compared using the Student's $t$-test, $P<0.05, n=3$.

endoplasmic reticulum. Collectively, these observations led to the discovery of the MRAP1 (Metherell et al. 2005), which will be discussed in section 'MC2R: physiology of the HPA-I axis in gnathostomes'.

Mountjoy et al. (1992) observed that human MC2R could be activated by ACTH, but not by NDP-MSH. This strict selectivity for ACTH, when compared with $\alpha$-MSH can be observed for the $X$. tropicalis $M C 2 R$ ortholog (Fig. 5A). In fact in every teleost and tetrapod $M C 2 R$ orthologs that have been analyzed, the MC2R ortholog can only be activated by ACTH, but not by any of the MSHsized ligands including NDP-MSH (Mountjoy et al. 1992, Klovins et al. 2004a, Ling et al. 2004, Agulleiro et al. 2010, Liang et al. 2011, Davis et al. 2013). The physiological implications of the strict ligand selectivity of teleost and tetrapod $M C 2 R$ orthologs will be discussed in section 'MC2R: physiology of the HPA-I axis in gnathostomes'.

The strict ligand selectivity requirements of teleost and tetrapod MC2R orthologs and the dependence of these orthologs on interaction with MRAP1 for functional expression are not shared by the MC2R ortholog of the cartilaginous fish, C. milii (elephant shark; Reinick et al. $2012 b$ ). The elephant shark MC2R ortholog could be functionally expressed in $\mathrm{CHO}$ cells without co-expression with an mrap cDNA. In addition, the elephant shark MC2R ortholog could be activated by either human ACTH(1-24) or NDP-MSH, and hACTH(1-24) was statistically a more potent ligand than NDP-MSH (Reinick et al. 2012b).

Published by Bioscientifica Ltd 
Finally, stimulation with cartilaginous fish (dogfish; Amemiya et al. 1999) melanocortin ligands resulted in the following hierarchy of ligand selectivity: ACTH(1-25)= $\gamma-\mathrm{MSH}=\delta-\mathrm{MSH}>\alpha-\mathrm{MSH}=\beta-\mathrm{MSH}$ (Reinick et al. 2012b).

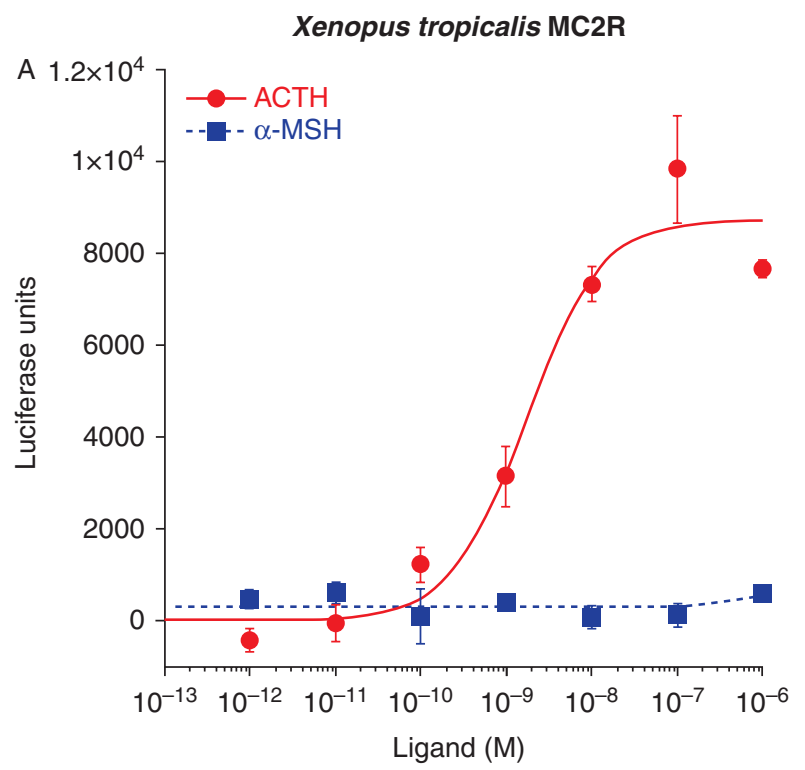

\begin{tabular}{|c|c|c|}
\hline MC1R & $\underline{\mathrm{EC}_{50}}$ & $\underline{P \text { value (vs ACTH) }}$ \\
\hline$\overline{\text { ACTH }}$ & $2.5 \times 10^{-9} \mathrm{M} \pm 3.2 \times 10^{-10}$ & \\
\hline$\alpha-\mathrm{MSH}$ & $2.6 \times 10^{-9} \mathrm{M} \pm 6.7 \times 10^{-10}$ & \\
\hline$\beta-\mathrm{MSH}$ & $7.0 \times 10^{-9} \mathrm{M} \pm 1.3 \times 10^{-9}$ & \\
\hline$\gamma$-MSH & $1.8 \times 10^{-8} \mathrm{M} \pm 4.0 \times 10^{-9}$ & 0.01 \\
\hline $\mathrm{ACTH}=$ & $\alpha-\mathrm{MSH}=\beta-\mathrm{MSH}>$ & $\gamma$-MSH \\
\hline \multicolumn{3}{|l|}{ MC2R } \\
\hline ACTH & $7.2 \times 10^{-9} \mathrm{M} \pm 1.6 \times 10^{-9}$ & \\
\hline$\alpha-M S H$ & NS & \\
\hline \multicolumn{3}{|l|}{ MC3R } \\
\hline$\overline{\mathrm{ACTH}}$ & $1.0 \times 10^{-11} \mathrm{M} \pm 2.1 \times 10^{-12}$ & \\
\hline$\alpha-M S H$ & $1.2 \times 10^{-10} \mathrm{M} \pm 3.6 \times 10^{-11}$ & 0.02 \\
\hline$\beta$-MSH & $2.7 \times 10^{-11} \mathrm{M} \pm 1.0 \times 10^{-11}$ & \\
\hline$\gamma$-MSH & $4.0 \times 10^{-11} \mathrm{M} \pm 1.0 \times 10^{-11}$ & 0.01 \\
\hline $\mathrm{ACTH}=$ & $\beta-\mathrm{MSH}>\quad \alpha-\mathrm{MSH}=$ & $\gamma-\mathrm{MSH}$ \\
\hline \multicolumn{3}{|l|}{ MC4R } \\
\hline ACTH & $9.2 \times 10^{-9} \mathrm{M} \pm 5.0 \times 10^{-9}$ & \\
\hline$\alpha-\mathrm{MSH}$ & $1.3 \times 10^{-8} \mathrm{M} \pm 3.0 \times 10^{-9}$ & \\
\hline$\beta$-MSH & $8.6 \times 10^{-9} \mathrm{M} \pm 7.7 \times 10^{-10}$ & \\
\hline$\gamma$-MSH & $9.4 \times 10^{-8} \mathrm{M} \pm 7.7 \times 10^{-9}$ & 0.001 \\
\hline $\mathrm{ACTH}=$ & $\alpha-\mathrm{MSH}=\beta-\mathrm{MSH}>$ & $\gamma$-MSH \\
\hline \multicolumn{3}{|l|}{ MC5R } \\
\hline$\overline{\text { ACTH }}$ & $1.5 \times 10^{-9} \mathrm{M} \pm 4.3 \times 10^{-10}$ & \\
\hline$\alpha-M S H$ & $1.5 \times 10^{-8} \mathrm{M} \pm 1.8 \times 10^{-9}$ & 0.001 \\
\hline$\beta$-MSH & $9.0 \times 10^{-9} \mathrm{M} \pm 2.2 \times 10^{-9}$ & 0.01 \\
\hline$\gamma$-MSH & $8.1 \times 10^{-9} \mathrm{M} \pm 1.9 \times 10^{-9}$ & 0.01 \\
\hline ACTH > & $\alpha-\mathrm{MSH}=\beta-\mathrm{MSH}=$ & $\gamma-\mathrm{MSH}$ \\
\hline
\end{tabular}

The potential physiological implications of these observations will be discussed in section 'MC2R: physiology of the HPA-I axis in gnathostomes'.

\section{MC2R: physiology of the HPA-I axis in gnathostomes}

The role of MC2R in the HPA-I axis of tetrapods and teleosts is one of the best examples of pharmacology matching physiology. The HPA-I axis plays a vital role in the daily regulation of metabolic homeostasis in tetrapods and teleosts and is most apparent during periods of chronic stress (Smith \& Valle 2006). As teleosts and tetrapods finally shared a common ancestor well over 400 million years ago (Sallan \& Coates 2010), the similarities in the HPI circuit in teleosts and the HPA circuit in mammals leads to the need to maintain the integrity of these circuits. As outlined in Fig. 6A, higher brain centers (hippocampus in mammals; Jacobson \& Sapolsky 1991) monitor several parameters including, but not limited to, the circulating levels of glucocorticoids, diurnal rhythms, and physiological perturbations that result from incidents of chronic stress. Integration of this information results in the release of corticotropinreleasing hormone (CRH) from neurons located in the hypothalamus (Vale et al. 1981). For tetrapods, the CRH neurons terminate at the median eminence, a portal vascular network that leads into the anterior pituitary gland (Sawchenko et al. 1993), and CRH binds to receptors on corticotropic cells (Bale \& Vale 2004). For teleosts, the $\mathrm{CRH}$ neurons terminate in close proximity to the corticotropic cells of the anterior pituitary and bind to their cognate receptors on corticotropes (Flik et al. 2006). The major secretory product of tetrapod and teleost corticotropic cells is ACTH, an end product derived from the precursor protein POMC (Fig. 2; Eipper \& Mains 1980) through the action of the endoprotease, proprotein convertase 1/3 (PC1/3; Seidah \& Chretien 1999). Hence, the end result is the same for tetrapods and teleosts; following the CRH-binding event, ACTH is released into

\section{Figure 5}

Ligand selectivity of Xenopus tropicalis MC2R. (A) The dose-response curves for $X$. tropicalis MC2R stimulated with either $X$. tropicalis ACTH (1-24) or $\alpha-\mathrm{MSH}$. These transfections were performed as described in the legend to Fig. 4 with the exception that a mouse Mrap cDNA construct was included for both transfections. In the absence of mouse MRAP, $X$. tropicalis MC2R cannot be functionally expressed (Liang et al. 2011). Mouse MRAP was used in this experiment due to the fact that at present a $X$. tropicalis mrap ortholog has not been detected in the genome of $X$. tropicalis. (B) A summary of the $\mathrm{EC}_{50}$ values for the ligand selectivity experiments in Figs 4 and $5 \mathrm{~A}$ is presented, $n=3$.

Published by Bioscientifica Ltd 
A

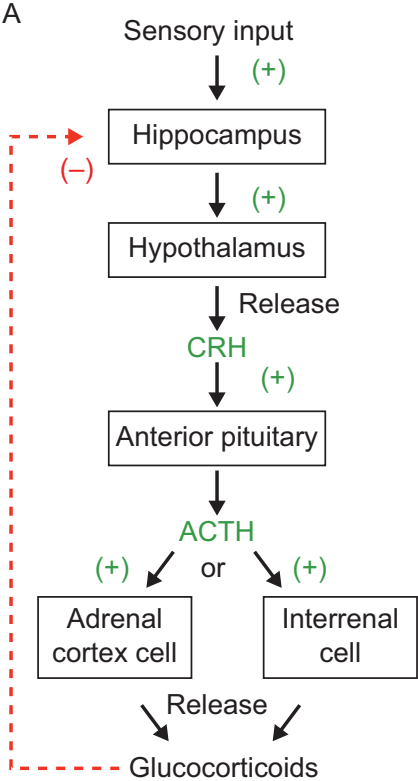

B

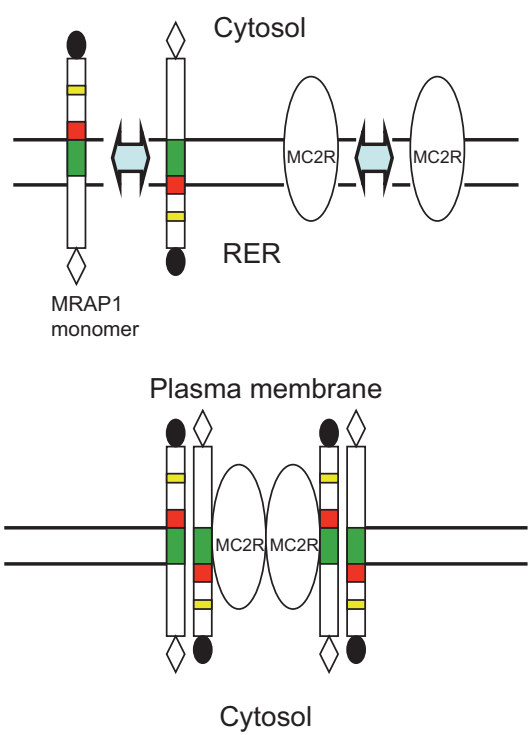

\section{Figure 6}

Overview of the hypothalamus/pituitary/adrenal-interrenal (HPA-I) axis and the interaction between MRAP and MC2R. (A) This figure presents a schematic of the HPA-I axis. CRH, corticotropin-releasing hormone; ACTH, adrenocorticotropin; $(+)$, stimulate; red dashed line, negative feedback. (B) MC2R monomers (oval figure) are inserted into the membrane of the rough endoplasmic reticulum (RER). MRAP1 monomers (rectangle) are also inserted into the RER membrane. MRAP1 monomer: the circle indicates the N-terminal of the monomer and the diamond the C-terminal of

the general circulation. ACTH, in turn, binds to MC2R on the adrenal cortex cells of mammals, birds, and reptiles or the interrenal cells of amphibians and teleosts, and the end result is also the same. The stimulated steroidogenic cells synthesize and release glucocorticoids (i.e. cortisol or corticosterone; Munck et al. 1984, Bamberger et al. 1996). Glucocorticoids, operating through an array of target cells, work to restore homeostasis by, for example, restoring glucose storage levels in the liver via the gluconeogenic pathway (a diurnal function), or by lowering an inflammatory response or an allergic response as a result of a chronic stress event.

The circuit is complicated, and damage to the hippocampal neurons that monitor glucocorticoid levels (McEwen 2000), defective CRH receptors on corticotropes (Timpl et al. 1998), mutations in the HFRW or KKRRP motifs of ACTH (Liang et al. 2013a) in the POMC gene, or a non-functional PC1/3 in corticotropic cells (Seidah \& Chretien 1999) could all shut down this circuit. At the level of adrenal cortex cells and interrenal cells, errors in the trafficking or activation of MC2R, or a defect in the glucocorticoid biosynthetic pathway will also disrupt the monomer. The green box represents the transmembrane domain of the MRAP1 monomer. The red box is the site of the motif for reverse topology. For mouse MRAP1, the amino acid sequence of this motif is LKANKNS (Hinkle \& Sebag 2009). The yellow box represents the activation motif in the MRAP1 monomer. For mouse MRAP1, the amino acid sequence of this motif is LDYI (Hinkle \& Sebag 2009). At the plasma membrane, the MC2R/MRAP1 complex is composed of a MC2R dimer and two MRAP1 dimers (Cooray et al. 2011).

the circuit. These pathologies in humans are congenital disorders such as familial glucocorticoid deficiency (FGD) and lipoid congenital adrenal hyperplasia. For example, type 1 FGD is the result of point mutations to the $m c 2 r$ gene, which either interfere with the trafficking of MC2R to the plasma membrane (Chung et al. 2008) or the activation of the mutated MC2R (Clark et al. 1993). Type 2 FGD is the result of mutations to the MRAP1 gene that either compromise the trafficking of MC2R to the plasma membrane or prevent MC2R from assuming a three-dimensional conformation that allows ACTH to activate the receptor (Metherell et al. 2005). Lipoid congenital adrenal hyperplasia is a defect in the cortisol biosynthetic pathway (Metherell et al. 2009). Theoretically, anyone of these syndromes could occur in a non-human tetrapod or a teleost, and the prediction would be that these conditions would be detrimental to the fitness of the organism.

For tetrapods and teleosts, the key to understanding the unique ligand selectivity properties of the HPA-I axis is the complex interaction between MC2R and MRAP1. The exclusive selectivity of MC2R for ACTH and the

Published by Bioscientifica Ltd 
inability of $\alpha$-MSH to even bind to mammalian MC2R (Buckley \& Ramachandran 1981, Mountjoy et al. 1992) are direct outcomes of this interaction. Studies on mammalian MRAP1 and MC2R orthologs have revealed a number of features of the MC2R/MRAP1 interaction and have raised several new questions. In brief, these studies indicate that in the absence of MRAP1, MC2R is missfolded and retained in the endoplasmic reticulum (Sebag \& Hinkle 2007). Conversely, in order for MRAP1 to facilitate the trafficking of MC2R to the plasma membrane, MRAP1 must form a homodimer with reverse topology (Sebag \& Hinkle 2009, Webb et al. 2009). The homodimer forms, apparently, as accessory protein monomers are inserted into the membrane of the endoplasmic reticulum (Fig. 6B). The latter observation raises the question as to how some monomers of MRAP1 are inserted into the membrane of the rough endoplasmic reticulum with $\mathrm{N}$ - to C-terminal orientation and other monomers are inserted with $\mathrm{C}$ - to N-terminal orientation. While this issue is not resolved, the amino acid motif in the N-terminal of MRAP1, which is required for reverse topology, has been identified (Fig. 6B; Sebag \& Hinkle 2009, Webb et al. 2009). In addition, the movement of MC2R to the plasma membrane requires contact between the single transmembrane domain of MRAP1 and an as yet undetermined transmembrane domain of MC2R. Bioluminescence resonance energy transfer analysis indicates that the mammalian MC2R/MRAP1 complex is a MC2R homodimer with two MRAP1 homodimers (Fig. 6B; Cooray et al. 2011). Once this complex is formed, the ligand selectivity properties of mammalian MC2R are dependent on a four amino acid motif in the N-terminal of MRAP1 (Fig. 6B) that is required to maintain MC2R in a three-dimensional orientation that blocks the binding of $\alpha-\mathrm{MSH}$, but allows interaction with the functional motifs on ACTH (i.e. the KR/KKRP motif and the HFRW motif). The significance of the four amino acid 'activation' motif in MRAP1 can be inferred from studies done with Mrap2, a paralog of Mrap1 (Hinkle \& Sebag 2009, Webb \& Clark 2010). Mammalian MRAP2 will facilitate the trafficking of MC2R to the plasma membrane, but this accessory protein cannot facilitate the activation of MC2R because MRAP2 orthologs lack the four amino acid 'activation motif' (Agulleiro et al. 2010, Liang et al. 2011). As shown in Fig. 6B, the four amino acid motif is on both MRAP1 monomers in the homodimer. At present, it is not known whether one or both of these motifs are responsible for inducing the functionally active three-dimensional structure of MC2R.

The features in mammalian MRAP1 required for the functional activation of mammalian MC2R (i.e. reverse topology domain, conserved transmembrane domain primary sequence, and the N-terminal 'activation' motif) are all present in teleost MRAP1 orthologs (Agulleiro et al. 2010), and teleost MC2R orthologs have the same ligand selectivity properties and MRAP requirements as tetrapod MC2R orthologs (Agulleiro et al. 2010, Liang et al. 2011). Collectively, these observations indicate that over the past 400 million years, as the ancestral bony vertebrates radiated into the modern day teleosts and tetrapods, the regulation of glucocorticoid synthesis and release by interrenal/adrenal cortex cells has been via the POMC cells of the anterior pituitary (corticotropes), which secrete ACTH, and not via those of the intermediate pituitary (melanotropes), which secrete $\alpha$-MSH and the other MSHsized end products, but the significance of this statement seems obscure as humans lack an intermediate pituitary gland. An organism such as the amphibian $X$. laevis having the ability to mediate the physiological color through activation of MC1R on chromatophores via the $\alpha-\mathrm{MSH} /$ intermediate pituitary pathway, but not to induce glucocorticoid synthesis and release by interrenal cells, has physiological implications. Although the importance of glucocorticoids in homeostasis is not disputed, chronic overproduction of glucocorticoids can have negative effects on the fitness of an organism by interfering with the intermediary metabolism, the immune response, and osmoregulation.

The intimate relationship between MC2R and MRAP1 during the evolution of the HPA-I axis raises questions with respect to origins. Has MRAP1 always been present in interrenal cells and did this transmembrane protein have some other functions before the association with MC2R? Conversely, have MC2R orthologs always been dependent on MRAP1 for functional expression? With respect to the former question, a recent study has provided some unexpected possibilities for alternative functions of MRAP1 based on the localization of MRAPs in different organelles of the cell (Roy et al. 2012). With respect to the latter question, before 2012, it was assumed that MC2R orthologs were all MRAP1 dependent and exclusively selective for ACTH. However, as noted in section 'Pharmacological studies of MCRs', the MC2R ortholog of the cartilaginous fish, C. milii, is MRAP1 independent and can be activated by either ACTH or the various cartilaginous fish MSH-sized ligands with varying degrees of efficacy. In fact, all of the cartilaginous fish melanocortin paralogs that have been analyzed can be activated by ACTH or the MSH-sized ligands (Liang et al. 2013b). While there is evidence that cartilaginous fish have an HPI axis (deRoos \& deRoos 1992, Nock et al. 2011), the

Published by Bioscientifica Ltd 
apparent lack of selectivity of the cartilaginous fish MCRs may be an indication that cartilaginous fishes have separate hypothalamus/anterior pituitary/interrenal and hypothalamus/intermediate pituitary/interrenal axes. At present, it is too early to predict whether these proposed circuits represent the physiological circuits unique to the cartilaginous fishes, or whether these proposed dual circuits are an ancestral feature of the gnathostomes.

\section{MC4R: physiology of energy homeostasis}

Neurons in the hypothalamus that express the MC4R are involved in the regulation of energy homeostasis and the regulation of feeding behavior (Cone 2006). It is beyond the scope of this review to discuss the roles that leptin, ghrelin, CRH, galanin, CART, and orexin play in this complex neuronal circuit (Leibowitz \& Wortley 2004); however, this section will comment on the interplay between the orexigenic NPY/AGRP neurons and the anorexigenic POMC neurons in this circuit (Fig. 7), which synapse with the MC4R neurons involved in the anorexigenic response. This circuit has been extensively studied in mammals (mice and rats; Cone 2006), and in the teleost, Danio rerio (zebrafish; Forlano \& Cone 2007), and the tetrapod and teleost circuits have several common features.

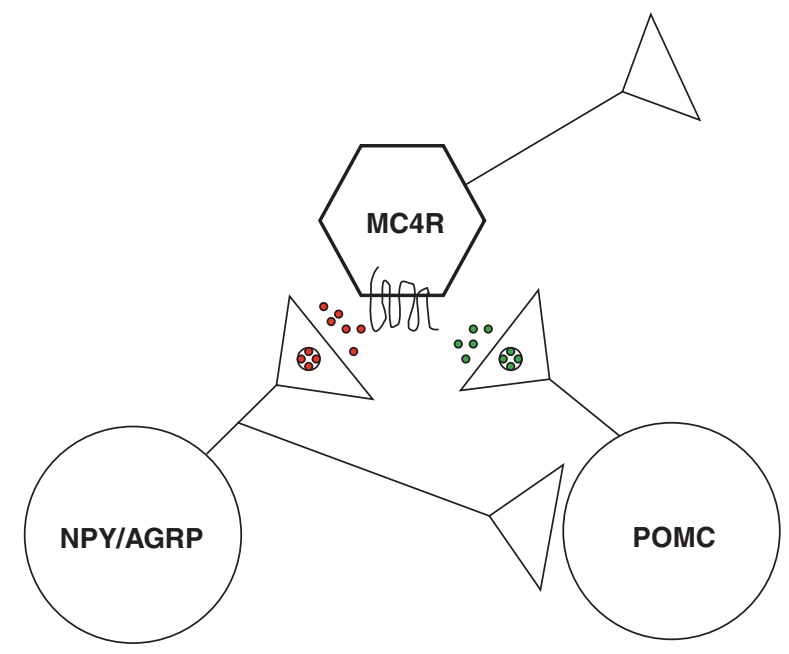

Figure 7

NPY/POMC circuit in the hypothalamus. This diagram depicts the orexigenic NPY/AGRP neuron and the anorexigenic POMC neurons, each forming a synapse with a neuron in the anorexigenic circuit that expresses the melanocortin 4 receptor (MC4R). The red circles represent AGRPs and NPY being released at the synapse from an NPY/AGRP neuron, and the green circles represent $\alpha-\mathrm{MSH}, \beta-\mathrm{MSH}, \gamma-\mathrm{MSH}$, and $\beta$-endorphin being released from a POMC neuron.
For example, in the rat hypothalamus, studies from the 1980s indicated that the end products in the POMC neurons in this circuit were non-acetylated $\alpha$-MSH (ACTH(1-13)amide), and $\beta$-endorphin (Gramsch et al. 1980). In the POMC neurons of the zebrafish hypothalamus, MSH-related end products are also present (Forlano \& Cone 2007). In the NPY neurons of both mammals and the zebrafish, NPY and AGRPs are co-localized in the same secretory vesicles (Cone 2006). When the anorexigenic POMC neurons are activated, the MC4R neurons are activated and the result is a decrease in feeding behavior among other outcomes. Conversely, when the orexogenic NPY/AGRP neurons are activated, an AGRP acts as a reverse agonist for MC4R and silences the MC4R neuron, thus allowing feeding behavior to proceed (Ollmann et al. 1997). In addition to this level of regulation, two recent studies (Asai et al. 2013, Sebag et al. 2013) have indicated that MRAP2 is another important regulator of MC4R in the MC4R-anorexigenic neurons in this circuit.

Capitalizing on the observation that there is a high degree of Mrap2 gene expression in the same region of the mouse hypothalamus where $M c 4 r$-expressing neurons are found, Asai et al. (2013) observed that Mrap $2^{-1-}$ mice or mice in which the Mrap2 gene is deleted in hypothalamic MC4R-anorexigenic neurons had early-onset obesity. Transient transfection of $\mathrm{CHO}$ cells with a mouse Mrap2 cDNA construct and a mouse $M c 4 r$ cDNA construct revealed that MRAP2 and MC4R could be co-immunoprecipitated, indicating that the two proteins may be forming a heterodimer complex. However, the most striking observation was that when Mrap2 and $M c 4 R$ were co-expressed, the activity of the receptor was enhanced and the result was a robust generation of cAMP in response to the stimulation by $\alpha-\mathrm{MSH}$, which greatly exceeded the response of $\mathrm{CHO}$ cells transiently transfected with $\mathrm{Mc} 4 r$ cDNA alone. Collectively, the Mrap2 knockout experiments and the Mrap2/Mc4r co-expression experiments indicate that Mrap2 can have a positive effect on the anorexigenic activity of $\mathrm{Mc} 4 \mathrm{r}$ neurons, and as a result feeding behavior is decreased. In support of these conclusions, a subset of human patients were identified with mutations in the MRAP2 gene; all these patients experienced early-onset obesity (Asai et al. 2013).

A study on the expression of mrap2 genes during the development of the zebrafish (Sebag et al. 2013) provided another example of the interplay between Mrap2 and Mc4r. The zebrafish has two mrap2 paralogous genes (mrap2a and mrap2b), which may be the result of the genome duplication event that occurred in the ancestral

Published by Bioscientifica Ltd 
teleost lineage (Meyer \& Van de Peer 2005). The mrap2a gene is expressed early in larval development during a period when the larvae should be maximizing food consumption. Accordingly, Sebag et al. (2013) observed that during periods of mrap2a expression, Mrap2 blocked the action of Mc4r, and growth was promoted. Conversely, the mrap $2 b$ gene is expressed later in development at a time when the organism is regulating the feeding rate. Mrap2b also interacts with MC4R. However, in this instance, the interaction increases the zebrafish Mc4r sensitivity for activation by $\alpha$-MSH in a manner nearly identical to the interaction between mouse MRAP2 and mouse MC4R (Asai et al. 2013). In addition, co-expression of zebrafish $m c 4 r$ with zebrafish mrap2a in HEK-293 cells results in an increase in the sensitivity of zebrafish MC4R for ACTH(1-24) (Agulleiro et al. 2013). Thus, zebrafish Mrap2b provides another mechanism for regulating the ligand selectivity of zebrafish Mc4r, and as a result modulating the feeding behavior and growth of older zebrafish.

Following the discovery of MRAP1 in 2005, and the subsequent discovery of MRAP2, it was unclear what role MRAP2 might be playing in the physiology of the MCRs (Hinkle \& Sebag 2009, Webb \& Clark 2010). The preceding studies indicate that a re-evaluation of the potential interactions between MRAP2 and the other MCRs should be performed.

\section{Conclusions}

While it appears that the MCR-mediating endocrine and neuronal circuits are unique to the chordates (Vastermark \& Schiöth 2011), the origin of this ligand/receptor interaction is obscure. What is clear, however, is that with the duplication of melanocortin paralogous genes, neofunctionalization has occurred (Force et al. 1999), as summarized in Fig. 1. Although there have been minor changes in the structure of the melanocortin ligands during the radiation of the chordates (Dores \& Baron 2011), unique MCR circuits have emerged to mediate pigmentation, glucocorticoid synthesis, energy homeostasis, and exocrine gland physiology (Cone 2006). While the evolution of the Mc2r gene in teleosts and tetrapods has resulted in a MCR paralog with very strict ligand properties, which facilitate proper functioning of the HPA-I axis, the other MCR paralogs are more generic in terms of ligand selectivity. However, as is apparent from the role that MC4R plays in energy homeostasis, other regulatory mechanisms in addition to ligand selectivity have emerged (i.e. AGRPs and MRAPs).
As more chordate genomes are sequenced, it is becoming apparent that among the gnathostomes (i.e. cartilaginous fishes, bony fishes including teleosts, and the tetrapods), five paralogous MCR genes are present, agrprelated genes are present in all the major groups, and the mrap2 gene is present in all of these genomes (Vastermark $\&$ Schiöth 2011). The question then to be resolved is, at which point in the radiation of the gnathostomes did MCR-mediated circuits begin the process of 'layering on' levels of regulation that involves the use of AGRP (polypeptides) and MRAPs.

\section{Declaration of interest}

The authors declare that there is no conflict of interest that could be perceived as prejudicing the impartiality of the review.

\section{Funding}

This review was supported by the Dewey and Debbie Long fund (R M D) to aid undergraduate research done by Nathan Dewey, and by $\mathrm{NIH}$ 1R15DK079282-01A1 and 2 R15 DK079282-02 735 (R L L). Graduate student support for Jeromy Prokop was provided by a grant from the College of Arts and Sciences, University of Akron.

\section{References}

Agulleiro MJ, Roy S, Sanchez E, Puchol S, Gallo-Payet N \& Cerdá-Reverter JM 2010 Role of melanocortin receptor accessory proteins in the function of zebrafish melanocortin receptor type 2. Molecular and Cellular Endocrinology 320 145-152. (doi:10.1016/j.mce.2010.01.032)

Agulleiro MJ, Cortés R, Fernández-Durán B, Navarro S, Guillot R, Meimaridou E, Clark AJL \& Cerdá-Reverter JM 2013 Melanocortin-4 receptor becomes an ACTH receptor by coexpression of melanocortin receptor accessory protein 2. Molecular Endocrinology 27 1934-1945. (doi:10.1210/me.2013-1099)

Amemiya Y, Takahashi A, Suzuki N, Sasayama Y \& Kawauchi H 1999 A newly characterized melanotropin in proopiomelanocortin in pituitaries of an Elasmobranch, Squalus acanthias. General and Comparative Endocrinology 114 387-395. (doi:10.1006/gcen.1999.7256)

Arends RJ, Vermeer H, Martens GJ, Leunissen JA, Wendelaar Bonga SE \& Flik G 1998 Cloning and expression of two proopiomelanocortin mRNAs in the common carp (Cyprinus carpio L.). Molecular and Cellular Endocrinology 143 23-31. (doi:10.1016/S0303-7207(98)00139-7)

Asai M, Ramachandrappa S, Joachim M, Shen Y, Zhang R, Nuthalapati N, Ramanathan V, Strochlic DE, Ferket P, Linhart K et al. 2013 Loss of function of the melanocortin 2 receptor accessory protein 2 is associated with mammalian obesity. Science 341 275-278. (doi:10.1126/science.1233000)

Bale TL \& Vale WW 2004 CRF and CRF receptors: role in stress responsivity and other behaviors. Annual Review of Pharmacology and Toxicology 44 525-557. (doi:10.1146/annurev.pharmtox.44.101802.121410)

Bamberger CM, Schulte HM \& Chrousos GP 1996 Molecular determinants of glucocorticoid receptor function and tissue sensitivity to glucocorticoids. Endocrine Reviews 17 245-261. (doi:10.1210/edrv-17-3-245)

Baron A, Veo K, Angleson J \& Dores RM 2009 Modeling the evolution of the MC2R and MC5R genes: studies on the cartilaginous fish, Heterondotus francisci. General and Comparative Endocrinology 161 13-19. (doi:10.1016/j.ygcen.2008.11.026) 
Buckley DI \& Ramachandran J 1981 Characterization of corticotropin receptors on adrenocortical cells. PNAS 78 7431-7435. (doi:10.1073/ pnas.78.12.7431)

Chepurny OG \& Holz GG 2007 A novel cyclic adenosine monophosphate responsive luciferase reporter incorporating a nonpalindromic cyclic adenosine monophosphate response element provides optimal performance for use in $\mathrm{G}$ protein coupled receptor drug discovery efforts. Journal of Biomolecular Screening 12 740-746. (doi:10.1177) 1087057107301856)

Chung TT, Webb TR, Chan LF, Cooray SN, Metherell LA, King PJ, Chapple JP \& Clark AJL 2008 The majority of ACTH receptor (MC2R) mutations found in familial glucocorticoid deficiency type 1 lead to defective trafficking of the receptor to the cell surface. Journal of Clinical Endocrinology and Metabolism 93 4948-4954. (doi:10.1210/jc. 2008-1744)

Clark AJL, McLoughlin L \& Grossman A 1993 Familial glucocorticoid deficiency associated with point mutation in the adrenocorticotropin receptor. Lancet 341 461-462. (doi:10.1016/0140-6736(93)90208-X)

Cone RD 2006 Studies on the physiological functions of the melanocortin system. Endocrine Reviews 27 736-749. (doi:10.1210/er.2006-0034)

Cooray SN, Chung T-T, Mazhar DK, Szidonia L \& Clark AJL 2011 Bioluminescence resonance energy transfer reveals the adrenocorticotropin (ACTH)-induced conformational change of the activated ACTH receptor complex in living cells. Endocrinology 152 495-502. (doi:10.1210/en.2010-1053)

Costa JL, Bui S, Reed P, Dores RM, Hochgeschwender U \& Brennan MB 2004 Mutational analysis of evolutionarily conserved ACTH residues. General and Comparative Endocrinology 136 12-16. (doi:10.1016/j.ygcen.2003. 11.005)

Davis P, Franquemont S, Liang L, Angleson JK \& Dores RM 2013 Review: Evolution of the melanocortin-2 receptor in tetrapods: studies on Xenopus tropicalis MC2R and Anolis carolinensis MC2R. General and Comparative Endocrinology 188 75-84. (doi:10.1016/j.ygcen.2013.04.007)

De Groot BL, van Aalten DM, Scheek RM, Amadei A, Vriend G \& Berendsen HJ 1997 Prediction of protein conformational freedom from distance constraints. Proteins 29 240-251. (doi:10.1002/(SICI)10970134(199710)29:2<240::AID-PROT11 > 3.0.CO;2-O)

Dores RM 2009 ACTH, the MSHs and the melanocortin receptors: revisiting the work of Robert Schwyzer - a 30 year retrospective. Annals of the New York Academy of Sciences 1163 93-100. (doi:10.1111/j.1749-6632. 2009.04434.x)

Dores R 2013 Observations on the evolution of the melanocortin receptor gene family: distinctive features of the melanocortin-2 receptor. Frontiers in Neuroscience 7 1-12. (doi:10.3389/fnins.2013.00028)

Dores RM \& Baron AJ 2011 Evolution of POMC: origin, phylogeny, posttranslational processing, and the melanocortins. Annals of the New York Academy of Sciences 1220 34-48. (doi:10.1111/j.1749-6632. 2010.05928.x)

Dores RM \& Lecaude S 2005 Trends in the evolution of the proopiomelanocortin gene. General and Comparative Endocrinology 142 81-93. (doi:10.1016/j.ygcen.2005.02.003)

Dores RM, Lecaude S, Bauer D \& Danielson PB 2002 Analyzing the evolution of the opioid/orphanin gene family. Mass Spectrometry Reviews 21 220-243. (doi:10.1002/mas.10029)

Eipper BA \& Mains RE 1980 Structure and biosynthesis of pro-adrenocorticotropin/endorphin and related peptides. Endocrine Reviews $\mathbf{1}$ 1-27. (doi:10.1210/edrv-1-1-1)

Flik G, Klaven PH, Van den Burg EH, Metz JR \& Huising MO 2006 CRF and stress in fish. General and Comparative Endocrinology 146 36-44. (doi:10.1016/j.ygcen.2005.11.005)

Force A, Lynch M, Pickett FB, Amores A, Yan YL \& Postlewait J 1999 Preservation of duplicate genes by complementary, degenerative mutations. Genetics 151 1531-1545.

Forlano PM \& Cone RD 2007 Conserved neurochemical pathways involved in hypothalamic control of energy homeostasis. Journal of Comparative Neurology 505 235-248. (doi:10.1002/cne.21447)
Forti FL, Dias MH \& Armelin HA 2006 ACTH receptor: ectopic expression, activity and signaling. Molecular and Cellular Biochemistry 293 147-160. (doi:10.1007/s11010-006-9237-0)

Gantz I \& Fong TM 2003 The melanocortin system. American Journal of Physiology. Endocrinology and Metabolism 284 E468-E474.

Gramsch C, Kleber G, Hollt V, Pasi A, Mehraein P \& Herz A 1980 Pro-opiomelanocortin fragments in human and rat brain, B-endorphin and $\alpha-\mathrm{MSH}$ are widely distributed in tissues of rodents. Endocrinology 121 1900-1907.

Haitina T, Klovins J, Andersson J, Fredriksson R, Lagerstrom MC, Larhammar D, Larson ET \& Schiöth HB 2004 Cloning, tissue distribution, pharmacology and three-dimensional modeling of melanocortin receptors 4 and 5 in rainbow trout suggest close evolutionary relationship of these subtypes. Biochemical Journal $\mathbf{3 8 0}$ 475-486. (doi:10.1042/BJ20031934)

Haitina T, Klovins J, Takahashi A, Löwgren M, Ringholm A, Enberg J, Kawauchi H, Larson ET, Fredriksson R \& Schiöth HB 2007 Functional characterization of two melanocortin (MC) receptors in lamprey showing orthology to the MC1 and MC4 receptor subtypes. BMC Evolutionary Biology 7101 (. (http://www.biomedcentral.com/14712148/7/101)) (doi:10.1186/1471-2148-7-101)

Haslach EM, Schaub JW \& Haskell-Luevano C 2009 ß-Turn secondary structure and melanocortin ligands. Bioorganic \& Medicinal Chemistry 17 952-958. (doi:10.1016/j.bmc.2008.02.090)

Hinkle PM \& Sebag JA 2009 Structure and function of the melanocortin 2 receptor accessory protein. Molecular and Cellular Endocrinology 300 25-31. (doi:10.1016/j.mce.2008.10.041)

Holland PW, Garcia-Fernandez J, Williams NA \& Sidow A 1994 Gene duplications and the origins of vertebrate development. Development (Supplement) 125-133

Horn F, Bettler E, Oliveira L, Campagne F, Cohen FE \& Vriend G 2003 GPCRDB information system for $\mathrm{G}$ protein-coupled receptors. Nucleic Acids Research 31 294-297. (doi:10.1093/nar/gkg103)

Jacobson L \& Sapolsky R 1991 The role of the hippocampus in feedback regulation of the hypothalamic-pituitary-adrenocortical axis. Endocrine Reviews 12 118-134. (doi:10.1210/edrv-12-2-118)

Kilianova Z, Basora N, Kilian P, Payet MD \& Gallo-Payet N 2006 Human melanocortin receptor 2 expression and functionality: effects of protein kinase A and protein kinase $\mathrm{C}$ on desensitization and internalization. Endocrinology 147 2325-2337. (doi:10.1210/en.2005-0991)

Klovins J, Haitina T, Fridmanis D, Kilianova Z, Kapa K, Fredriksson R, Gallo-Payet N \& Schiöth HB 2004a The melanocortin system in Fugu: determination of POMC/AGRP/MCR gene repertoire and synteny, as well as pharmacology and anatomical distribution of the MCRs. Molecular Biology and Evolution 21 563-579. (doi:10.1093/molbev/ msh050)

Klovins J, Haitina T, Ringholm A, Lowgren M, Fridmanis D, Slaidina M, Stier S \& Schiöth HB 2004b Cloning of two melanocortin (MC) receptors in spiny dogfish. European Journal of Biochemistry $\mathbf{2 7 1}$ 4320-4331. (doi:10.1111/j.1432-1033.2004.04374.x)

Leibowitz SF \& Wortley KE 2004 Hypothalamic control of energy balance: different peptides, different functions. Peptides 25 473-504. (doi:10.1016/j.peptides.2004.02.006)

Liang L, Angleson JK \& Dores RM 2013a Review: The human melanocortin2 receptor - a model system for analyzing hormone/receptor interactions in the HPA axis. General and Comparative Endocrinology 181 203-210. (doi:10.1016/j.ygcen.2012.11.011)

Liang L, Reinick C, Angleson JK \& Dores RM 2013b Mini-review: Evolution of melanocortin receptors in cartilaginous fish: melanocortin receptors and the stress axis in elasmobranches. General and Comparative Endocrinology 181 4-9. (doi:10.1016/j.ygcen.2012.08.016)

Liang L, Sebag JA, Eagelston L, Serasinghe MN, Veo K, Reinick C, Angleson J, Hinkle PM \& Dores RM 2011 Functional expression of frog and rainbow trout melanocortin 2 receptors using heterologous MRAP1s. General and Comparative Endocrinology 174 5-14. (doi:10.1016/j.ygcen. 2011.07.005)

Published by Bioscientifica Ltd 
Ling MK, Hotta E, Kilanova Z, Haitina T, Ringholm A, Johansson L, GalloPayet N, Takeuchi S \& Schhioth HN 2004 The melanocortin receptor subtypes in chicken have high preference to ACTH-derived peptides. British Journal of Pharmacology 143 626-637. (doi:10.1038/sj.bjp. 0705900)

McEwen BS 2000 The neurobiology of stress: from serendipity to clinical relevance. Brain Research 886 172-189. (doi:10.1016/S00068993(00)02950-4)

Metherell LA, Chapple JP, Cooray S, David A, Becker C, Ruschendorf F, Naville D, Begeot M, Khoo B, Nurnberg P et al. 2005 Mutations in MRAP, encoding a new interacting partner of the ACTH receptor, cause familial glucocorticoid deficiency type 2. Nature Genetics 37 166-170. (doi:10.1038/ng1501)

Metherell LA, Naville D, Halabi G, Begeot M, Huebner A, Nürnberg G, Nürnberg P, Green J, Tomlinson JW, Krone NP et al. 2009 Non-classic lipoid congenital adrenal hyperplasia masquerading as familial glucocorticoid deficiency. Journal of Clinical Endocrinology and Metabolism 94 3865-3871. (doi:10.1210/jc.2009-0467)

Meyer A \& Van de Peer Y 2005 From 2R to 3R: evidence for a fish-specific genome duplication (FSGD). BioEssays 27 937-945. (doi:10.1002/bies. 20293)

Mountjoy KG, Robbins LS, Mortrud MT \& Cone RD 1992 The cloning of a family of genes that encode the melanocortin receptors. Science $\mathbf{2 5 7}$ 1248-1251. (doi:10.1126/science.1325670)

Munck A, Guyre PM \& Holbrook NJ 1984 Physiological functions of glucocorticoids in stress and their relation to pharmacological actions. Endocrine Reviews 5 25-44. (doi:10.1210/edrv-5-1-25)

Nakanishi S, Inoue A, Kita T, Nakamura M, Chung AC, Cohen SN \& Numa S 1979 Nucleotide sequence of cloned cDNA for bovine corticotropinB-lipotropin precursor. Nature 278 423-427. (doi:10.1038/278423a0)

Nock TG, Chand D \& Lovejoy DA 2011 Identification of members of the gonadotropin-releasing hormone (GnRH), corticotropin-releasing factor (CRF) families in the genome of the holocephalon, Callorthincus milii (elephant shark). General and Comparative Endocrinology 171 237-244. (doi:10.1016/j.ygcen.2011.02.001)

Ohno S, Wolf U \& Atkins NB 1968 Evolution from fish to mammals by gene duplication. Hereditas 59 169-187. (doi:10.1111/j.1601-5223.1968. tb02169.x)

Ollmann MM, Wilson BD, Yang YK, Kerns JA, Chen Y, Gantz I \& Barsh GS 1997 Antagonism of central melanocortin receptors in vitro and in vivo by agouti-related protein. Science 278 135-138. (doi:10.1126/science. 278.5335.135)

Pogozheva ID, Chai B-X, Lomize AL, Fong TM, Weinberg DH, Nargund RP, Mulholland MH, Grantz I \& Mosberg HI 2005 Interactions of human melanocortin 4 receptors with nonpeptide and peptide agonists. Biochemistry 44 11329-11341. (doi:10.1021/bi0501840)

Rached M, El Mourabit H, Buronfosse A, Blondet A, Naville D, Begeot M \& Penhoat A 2005 Expression of the human melanocortin-2 receptor in different eukaryotic cells. Peptides 26 1842-1847. (doi:10.1016/j. peptides.2004.11.037)

Reinick CL, Liang L, Angleson JK \& Dores RM 2012a Functional expression of Squalus acanthias melanocortin 5 receptor in CHO Cells, ligand selectivity and interaction with MRAP. European Journal of Pharmacology 680 1-7. (doi:10.1016/j.ejphar.2012.01.021)

Reinick CL, Liang L, Angleson JK \& Dores RM $2012 b$ Identification of an MRAP-independent melanocortin-2 receptor: functional expression of the cartilaginous fish, Callorhinchus milii, melanocortin-2 receptor in CHO cells. Endocrinology 153 4757-4765. (doi:10.1210/en. 2012-1482)

Ringholm A, Fredriksson R, Poliakova N, Yan Y, Postlethwait JH, Larhammar D \& Schiöth HB 2002 One melanocortin 4 and two melanocortin 5 receptors from zebrafish show remarkable conservation in structure and pharmacology. Journal of Neurochemistry 82 6-18. (doi:10.1046/j.1471-4159.2002.00934.x)

Ringholm A, Klovins J, Fredriksson R, Poliakova N, Larson ET, Kukkonen JP, Larhammar D \& Schiöth HB 2003 Presence of melanocortin (MC4) receptor in spiny dogfish suggests an ancient vertebrate origin of central melanocortin system. European Journal of Biochemistry 270 213-221. (doi:10.1046/j.1432-1033.2003.03371.x)

deRoos R \& deRoos CC 1992 Effects of mammalian ACTH on potential fuels and gluconeogenic substrates in the plasma of the spiny dogfish shark (Squalus acanthias). General and Comparative Endocrinology 87 149-158. (doi:10.1016/0016-6480(92)90161-C)

Roy S, Rached M \& Gallo-Payet N 2007 Differential regulation of the human adrenocorticotropin receptor [melanocortin-2 receptor (MC2R)] by human MC2R accessory protein isoforms $\alpha$ and $\beta$ in isogenic human embryonic kidney 293 cells. Molecular Endocrinology 21 1656-1669. (doi:10.1210/me.2007-0041)

Roy S, Roy SJ, Pinars S, Aquilleiro MJ, Cerde-Reverter JM, Parent J-L \& Gallo-Payet N 2012 The C-terminal domains of melanocortin-2 receptor (MC2R) accessory protein (MRAP1) influence their localization and ACTH-induced cAMP production. General and Comparative Endocrinology 176 265-274. (doi:10.1016/j.ygcen.2012.02.003)

Sallan LC \& Coates MI 2010 End-Devonian extinction and a bottleneck in the early evolution of modern jawed vertebrates. PNAS $\mathbf{1 0 7}$ 10131-10135. (doi:10.1073/pnas.0914000107)

Sawchenko PE, Imaki T, Potter E, Kovacs K, Kimaki J \& Vale W 1993 The functional neuroanatomy of corticotropin-releasing factor. Ciba Foundation Symposium 172 5-21.

Sawyer TK, Sanfilippo PJ, Hruby V, Engel MH, Heward CB, Burnett JB \& Hadley ME 1980 4-Norleucine, 7-D-phenylalanine- $\alpha$-melanocytestimulating hormone: a highly potent $\alpha$-melanotropin with ultralong biological activity. PNAS $\mathbf{7 7}$ 5754-5758. (doi:10.1073/pnas.77.10.5754)

Schiöth HB, Haitina T, Ling MK, Ringholm A, Fredriksson R, Cerda-Reverter JM \& Klovin J 2005 Evolutionary conservation of the structural, pharmacological, and genomic characteristics of the melanocortin receptor subtypes. Peptides 26 1886-1900. (doi:10.1016/j.peptides. 2004.11.034)

Schwyzer R 1977 ACTH: a short introductory review. Annals of the New York Academy of Sciences 297 3-26. (doi:10.1111/j.1749-6632.1977. tb41843.x)

Sebag JA \& Hinkle PM 2007 Melanocortin-2 receptor accessory protein MRAP forms antiparallel homodimers. PNAS 104 20244-20249. (doi:10.1073/pnas.0708916105)

Sebag JA \& Hinkle PM 2009 Regions of melanocortin 2 (MC2) receptor accessory protein necessary for duel topology and MC2 receptor trafficking and signaling. Journal of Biological Chemistry 284 610-618. (doi:10.1074/jbc.M804413200)

Sebag JA, Zhang C, Hinkle PM, Bradshaw AM \& Cone RD 2013 Developmental control of the melanocortin-4 receptor by MRAP2 proteins in zebrafish. Science $\mathbf{3 4 1}$ 278-281. (doi:10.1126/science. 1232995)

Seidah N \& Chretien M 1999 Proprotein and prohormone convertases: a family of subtilases generating diverse bioactive polypeptides. Brain Research 848 45-62. (doi:10.1016/S0006-8993(99)01909-5)

Smith SM \& Valle WW 2006 The role of the hypothalamus-pituitaryadrenal axis in neuroendocrine responses to stress. Dialogues in Clinical Neuroscience 8 383-395.

Sundstrom G, Dreborg S \& Larhammar D 2010 Concomitant duplication of the opioid peptide and receptor genes before the origin of jawed vertebrates. PLoS ONE 5 e10512. (doi:10.1371/journal.pone.0010512)

Takahashi A \& Kawauchi H 2006 Evolution of melanocortin systems in fish. General and Comparative Endocrinology 148 85-94. (doi:10.1016/j.ygcen. 2005.09.020)

Takahashi A, Amemiya Y, Nozaki M, Sower SA \& Kawauchi H 2001 Evolutionary significance of proopiomelanocortin in agnathan and chondrorichthyes. Comparative Biochemistry and Physiology. Part B, Biochemistry and Molecular Biology 129 283-289. (doi:10.1016/S10964959(01)00330-X)

Takahashi A, Itoh A, Nakanishi T, Amemiya A, Ida Y, Meguro H \& Kawauchi H 2004 Molecular cloning of proopiomelanocortin cDNA in 
the ratfish a holocephalan. General and Comparative Endocrinology 135 159-165. (doi:10.1016/j.ygcen.2003.08.007)

Timpl P, Spanagel R, Sillaber I, Kresse A, Reul JM, Stalla GK, Blanquet V, Steckler T, Holsboer F \& Wurst W 1998 Impaired stress response and reduced anxiety in mice lacking a functional corticotropin-releasing hormone receptor 1. Nature Genetics 19 162-166. (doi:10.1038/520)

Vale W, Spiess J, Rivier C \& Rivier J 1981 Characterization of a 41-residue ovine hypothalamic peptide that stimulates secretion of corticotropin and $\beta$-endorphin. Science 213 1394-1397. (doi:10.1126/science.6267699)

Vallarino M, d'Amora M \& Dores RM 2012 New insights into the neuroanatomical distribution and phylogeny of opioids and POMCderived peptides in fish. General and Comparative Endocrinology 177 338-347. (doi:10.1016/j.ygcen.2012.04.014)

Vassilatis DK, Hohmann JG, Zeng H, Li F, Ranchalis JE, Mortrud MT, Brown A, Rodriguez SS, Weller JR, Wright AC et al. 2003 The G proteincoupled receptor repertoires of human and mouse. PNAS 49034908.
Vastermark A \& Schiöth HB 2011 The early origin of melanocortin receptors, agouti-related peptide, agouti signaling peptide, and melanocortin receptor-accessory proteins, with emphasis on pufferfishes, elephant shark, lampreys, and amphioxus. European Journal of Pharmacology 660 61-69. (doi:10.1016/j.ejphar.2010.10.106)

Webb TR \& Clark AJ 2010 Minireview: The melanocortin 2 receptor accessory proteins. Molecular Endocrinology 24 475-484. (doi:10.1210/ me.2009-0283)

Webb TR, Chan LF, Cooray SN, Cheetham ME, Chapple JP \& Clark AJ 2009 Distinct melanocortin 2 receptor accessory protein domains are required for melanocortin 2 receptor interaction and promotion of receptor trafficking. Endocrinology 150 720-726. (doi:10.1210/en.20080941)

Xu D \& Zhang Y 2012 Ab initio protein structure assembly using continuous structure fragments and optimized knowledge-based force field. Proteins 80 1715-1735. (doi:10.1002/prot.24105)

Received in final form 30 April 2014

Accepted 6 May 2014
C 2014 Society for Endocrinology Printed in Great Britain
Published by Bioscientifica Ltd 